\title{
Percepções das relações entre violência sexual e bullying a partir das vivências de adolescentes d:
}

\author{
Grazielli Fernandes $^{\text {a }}{ }^{(}$, , \& Maria Angela Mattar Yunes $^{\text {b }} \mathbb{( i b}^{2}$ \\ Universidade La Salle, Canoas, Brasil ${ }^{\text {a }}$ : Universidade Salgado de Oliveira, \\ Niterói, Brasil ${ }^{\text {b }}$
}

\section{RESUMO}

Esta pesquisa teve por objetivo compreender relações entre os efeitos de duas formas de violência, a violência sexual e o bullying, na vida de adolescentes escolares. Trata-se de um estudo de caso realizado em uma escola pública do sul do Brasil do qual participaram quatro adolescentes do sexo feminino. Os instrumentos de coleta de dados foram: Entrevista Reflexiva e fichas documentais escolares. Para a análise dos dados, utilizou-se a grounded-theory. Constatou-se que as participantes adotavam estratégias de coping de negação do papel de vítimas de violência familiar com pouco sucesso no ambiente educacional. Em consequência do sofrimento da violência sexual que as fragilizou emocionalmente, elas trocar alvos por vítimas de bullying. Apesar disso, todas evidenciaram percepção ecológico-sistêmica das interações dos efeitos negativos das duas modalidades de violência em suas vidas.

\section{Palavras-chave}

Adolescência; Violência sexual; Bullying

\begin{abstract}
This research aimed to understand the relationship between the effects of two types of violence, sexual abuse and bullying, in the life of school adolescents. This is a case study developed in a public school in southern Brazil. Four female adolescents participated. The instruments of data collection were: Reflexive Interviews and school document records. Grounded-theory was used to analyse the data. The results showed that the participants adopted coping strategies such as denying the role of victims of family violence, with low success in the educational environment. The suffering of sexual abuse showed that being emotionally debilitated made them to be targets for victims of bullying. Nevertheless, they showed an ecological-systemic perception of the interactions of the negative effects of the two types of violence in their lives.
\end{abstract}

\section{Keywords}

Adolescence; Sexual violence; Bullying.

\footnotetext{
1 Correspondence about this article should be addressed to Grazielli Fernandes: graziellifernandes@gmail.com

2 Conflicts of Interest: The authors declare that the research was conducted in the absence of any commercial or financial relationships that could be construed as a potential conflict of interest.
} 
Perceptions of the Relationship Between Sexual Abuse and Bullying from the Experiences of Adolescents

\section{Introdução}

A violência acompanha a existência da humanidade e tem sido tratada como um problema de saúde pública que deve ser prevenido com políticas públicas e serviços adequados e eficazes. Embora tenha estado sempre presente na sociedade, não se deve aceitar a violência como um aspecto inevitável da condição humana (Souza \& Minayo; 2005). Souza e Minayo (2005) classificam a violência de diferentes formas: violências autoinfligidas, que são os comportamentos suicidas e os autoabusos; violências interpessoais, que são classificadas em dois âmbitos, intrafamiliar ou violência doméstica (entre os parceiros íntimos e entre os membros da família, principalmente no ambiente da casa) e comunitária (no ambiente social em geral, entre conhecidos e desconhecidos); violências coletivas, que são os atos violentos nos âmbitos macrossociais, políticos e econômicos e caracterizam a dominação de grupos e do Estado (Souza \& Minayo, 2005).

$\mathrm{O}$ direito de crianças e adolescentes de viverem em ambientes sem violência é garantido legalmente, como descrito na Convenção sobre os Direitos da Criança, no âmbito mundial; na Constituição da República Federativa do Brasil (artigo 227) e no Estatuto da Criança e do Adolescente (Lei n. 8.069, de 13 de julho de 1990), especificamente no cenário brasileiro. Embora tais direitos estejam garantidos em lei, as crianças e adolescentes ainda são vítimas de diferentes formas de violência (World Health Organization [WHO], 2006). Essa violência está relacionada à transgressão do poder, dever e proteção do adulto, mas também à negação do direito que eles têm de serem tratados como sujeitos e indivíduos em condição peculiar de desenvolvimento (Azevedo et al., 2018).

Dentre as formas de violência doméstica (VD) a que crianças e adolescentes estão expostos, citam-se a violência sexual (VS) e o bullying, especificamente tratados neste estudo. A primeira é definida como envolvimento de uma criança em atividade sexual que ela não compreende totalmente, não consegue dar consentimento informado ou para a qual não está preparada, ou que viole as leis ou normas sociais (Ministério da Saúde, 2002). A VS é também tratada como um problema de gênero, tendo em vista que as maiores vítimas são as mulheres, "incorporando representações sociais historicamente construídas e relações de dominação, que designam a homens e mulheres papéis e oportunidades desiguais na sociedade" (Deslandes et al., 2016, p. 866). No Brasil, apenas 
na cidade de Recife, entre os anos de 2012 e 2013, houve a notificação de 328 crianças e adolescentes vítimas de VS, sendo a maioria delas do sexo feminino (92,1\%), na faixa etária de 10 a 14 anos (59,2\%) (Sena et al., 2018). No cenário nacional, dados da Pesquisa Nacional de Saúde do Escolar (PeNSE) em, 2015, revelou um perfil geral das vítimas de VS: idade menor que 13 anos, sexo feminino, cor da pele preta, ser agredido por familiares. As consequências para as vítimas, relatadas nesse estudo, foram insônia, solidão, consumir tabaco/álcool regularmente, ter experimentado drogas, ter iniciado atividade sexual. Além disso, são caracterizadas por não possuírem amigos, sentirem-se inseguras na escola ou no trajeto escola-casa e terem sofrido bullying (Santos et al., 2019).

Já o bullying, um subtipo de violência escolar, existe quando alguém é exposto, repetidamente e ao longo do tempo, a ações negativas intencionais por parte de um ou mais alunos. Está presente nessa dinâmica, também, o desequilíbrio de poder entre autor e vítima, o qual tem dificuldades de se defender (Olweus, 1993, 2019). Pode ser praticado de forma direta (física e verbal) ou indireta (exclusão social, prática de espalhar rumores e fofocas e cyberbullying) (Smith, 2014). Conforme a literatura, os papéis desempenhados são: vítima (ou alvo), vítima agressora, agressor (ou autor) e observador (ou testemunha).

A vítima passiva é aquela que não tem condições de se defender e está exposta às agressões (Olweus, 1993), sendo caracterizada como ansiosa, insegura, submissa, com baixa autoestima e uma visão negativa sobre si mesma (Olweus, 1993). A vítima agressora é quem sofre e pratica bullying ao mesmo tempo, mas contra outros colegas que não sejam seu agressor. Sente necessidade de humilhar seus pares para encobrir suas próprias limitações (Volk et al., 2014). O agressor é aquele que vitimiza os mais fracos e sente necessidade de dominar e maltratar seus pares (Olweus, 1993). Tem um desejo de obter status no grupo e não sente medo de ser confrontado (Berger, 2007; Salmivalli, 2010). Tem como características hiperatividade e impulsividade (Vaughn et al., 2010), pouca empatia e uma visão positiva sobre si mesmo (Olweus, 1993). O observador é aquele que não agride diretamente, mas desempenha um papel fundamental nas dinâmicas de bullying (Cowie, 2014). Salmivalli (2010) definiu as testemunhas em quatro tipos: as que adotam a lei do silêncio; as que tentam defender a vítima; as que manifestam apoio ao agressor; e as que atuam como assistentes do agressor.

O bullying escolar não é um fenômeno recente, cujos primeiros estudos datam do século XIX (Berger, 2007; Smith, 2014), sendo parte integrante da rotina escolar. No Brasil, um estudo com 2.293 adolescentes de escolas públicas e privadas revelou que $41 \%$ desses estudantes relataram vitimização e $29,1 \%$ agressão por bullying. Dos que se 
declararam vítimas, 37,5\% afirmaram não reagir com tanta frequência como foram agredidos. Metade dos alunos (50,9\%) identificou-se como vítima sem praticar nenhum tipo de agressão contra outro colega (Reisen et al., 2019).

A teoria bioecológica do desenvolvimento humano, de Urie Bronfenbrenner (2011), entende que os seres humanos estão em constante interação com os múltiplos ambientes nos quais atuam direta ou indiretamente. Essa abordagem compreende que todas as ações, interações e redes estabelecidas em um ambiente podem se refletir nos demais, a depender das conexões ou desconexões entre os sistemas. Por esse motivo, é possível estabelecer interfaces entre a VS e o bullying, abordados neste estudo.

Os ambientes, ou contextos ecológicos, são caracterizados por Bronfenbrenner (1996, 2011) como: microssistema, mesossistema, exossistema e macrossistema. O microssistema refere-se a sistemas próximos, de relações face a face, como a família e a escola. O mesossistema envolve as relações entre dois ou mais ambientes nos quais a pessoa participa ativamente (por exemplo, as relações entre família e escola). O exossistema envolve as ligações indiretas da pessoa em desenvolvimento (ela não está presente, mas é influenciada de forma indireta - por exemplo, o trabalho dos pais/responsáveis). O macrossistema é a união das características do micro, meso e exossistemas de determinada cultura ou contexto social mais amplo.

Com o aporte da Bioecologia do Desenvolvimento Humano, entende-se que as pessoas vivem e se desenvolvem em uma rede de relações (Bronfenbrenner, 1996) que se inicia no ambiente familiar. É na família que a criança encontra os primeiros “outros”, com os quais aprende a existir no mundo, o qual passa a ter um significado a partir das trocas intersubjetivas, construídas pelo afeto (Szymanski, 2004). Com o passar dos anos, as crianças passam a estabelecer novos vínculos e assumem novos papéis sociais nos ambientes em que circulam, como a escola (Bronfenbrenner, 1996, 2011). Esse ambiente escolar propicia o aprendizado de novas habilidades sociais e nele são construídos vínculos de amizade e companheirismo, pois representa a abertura para o espaço social fora do lar (Hoppe \& Ramos, 2012).

Tanto na escola quanto na família as pessoas podem estabelecer vínculos positivos e negativos. Os processos de risco (interações negativas), como VS e bullying, aumentam a possibilidade de a pessoa apresentar problemas físicos, sociais ou emocionais (Marzol et al., 2012). Nas situações estressoras ou diante de fatores de risco, a pessoa em desenvolvimento pode adotar estratégias de coping, que se define por um conjunto de esforços cognitivos e comportamentais intencionais que auxiliam a lidar com tais eventos 
negativos. Quando bem-sucedido, o coping alivia tensões decorrentes das vivências (Lazarus \& Folkman, 1984).

É preciso atentar para a complexidade desses fenômenos em estudos com crianças e adolescentes. De fato, estudos recentes apontam relações intrínsecas entre violência doméstica e bullying. No Canadá, pesquisa conduzida por Hébert e colaboradores (2016) demonstra que meninas e meninos abusados sexualmente são mais propensos a sofrer bullying, em comparação a adolescentes não vitimizados. Entretanto, apesar de reconhecerem que são vítimas de violência, muitos adolescentes podem, ainda assim, identificar seus agressores como vínculos positivos (Fernandes et al., 2020). Isso pode ser um reflexo da naturalização da violência socialmente arraigada na crença do processo educativo, especialmente por meio de medidas coercitivas e punitivas (Magalhães et al., 2017).

A partir de tais considerações, este estudo teve por objetivo compreender relações e os efeitos da violência sexual e do bullying a partir da vivência de adolescentes escolares. A hipótese deste estudo é de que as adolescentes reconheçam as relações entre ambas as formas de violência e os efeitos negativos advindos dessa vitimização. A construção metodológica do estudo de caso num contexto escolar público buscou oferecer aos participantes um espaço importante de diálogo e de reflexão sobre vivências de violências.

\section{Método}

Trata-se de um estudo qualitativo, do tipo estudo de caso, realizado em uma escola pública localizada no sul do Brasil, que associa duas estratégias metodológicas: Entrevista Reflexiva e fichas escolares das estudantes.

\section{Participantes}

Participaram deste estudo quatro adolescentes do sexo feminino, com idades entre 12 e 17 anos, estudantes dos anos finais do Ensino Fundamental, que declararam ter sofrido VS e estarem envolvidas em situação de bullying. As estudantes foram selecionadas a partir de duas etapas anteriores, conduzidas pela mesma pesquisadora e descritas a seguir. 


\section{Instrumentos}

Na primeira etapa de seleção, 112 adolescentes responderam a três instrumentos: a) Questionário de dados sociodemográficos; b) Questionário sobre bullying (Bandeira, 2009), com 15 questões de múltipla escolha em que os participantes podem se identificar como envolvidos ou não em bullying; c) Questionário de Juventude Brasileira (Dell'Aglio et al., 2011), de caráter quantitativo, que possibilita investigar situações de diferentes formas de VD vivenciadas no contexto familiar, dentre elas a VS. Optou-se por utilizar tais instrumentos para a seleção por já terem sido testados e utilizados no contexto brasileiro (Zappe \& Dell'Aglio, 2016; Bandeira e Hutz, 2010). A partir do cruzamento entre ambos os questionários (bullying e violência doméstica), foram selecionados todos os adolescentes que declararam estar envolvidos em violência doméstica e bullying, totalizando 15 estudantes (10 meninas e cinco meninos).

$\mathrm{Na}$ segunda etapa, com os 15 adolescentes, foi utilizado o Mapa dos Cinco Campos (Hoppe, 1998), instrumento que permite conhecer e avaliar o funcionamento da rede de relações dos participantes, observando a quantidade e a qualidade dos vínculos estabelecidos em diferentes contextos (Siqueira et al., 2006). Nessa fase, o foco foi avaliar as relações dos adolescentes em dois campos: Escola e Família. A partir dos dados obtidos, foram selecionados oito adolescentes, entre 12 e 17 anos, sendo seis meninas e dois meninos (Fernandes et al., 2016), todos vítimas de VD e bullying. Fazem parte desse grupo as quatro adolescentes vítimas de VS, cujas experiências são consoantes com o interesse deste estudo, portanto, trata-se de um recorte de uma pesquisa mais ampla.

Por fim, na terceira etapa do estudo, realizou-se a Entrevista Reflexiva, que originalmente parte de um contato inicial e apresenta uma ou mais questões norteadoras, elaboradas de acordo com o objetivo do trabalho. A partir dessa(s) questão(ões), esperase que o entrevistado discorra livremente. As questões norteadoras desta pesquisa foram: "Então, conta sobre sua vida na família e na escola", "Como tu percebes a ligação entre esses dois lugares em que tu vives, a partir das situações de violência doméstica e bullying por ti vivenciadas? Fale sobre isso". Nesta segunda pergunta norteadora, emergiram diferentes formas de VD, dentre elas a VS, tópico de interesse desta pesquisa. O segundo encontro ocorre logo após a pré-análise dos dados do primeiro, para que uma relação de entrevista reflexiva seja efetivamente construída (Yunes \& Szymanski, 2005).

As fichas documentais escolares, que apresentam informações importantes sobre a vida dos alunos, também foram disponibilizadas às pesquisadoras. Esse registro é 
realizado principalmente pelo Orientador Escolar. A partir dessas fichas, as pesquisadoras puderam obter detalhes importantes sobre a vida das adolescentes. Assim, antes de a pesquisadora iniciar a Entrevista Reflexiva com cada participante, realizou a leitura atenta de tais fichas.

\section{Procedimentos da Entrevista Reflexiva}

Durante o primeiro encontro da Entrevista Reflexiva, inicialmente, a pesquisadora agradece a participação, relembra novamente o objetivo da pesquisa e os aspectos éticos. Após, introduz a primeira pergunta norteadora e, durante o discurso, a segunda pergunta. De forma gradativa, a entrevistadora vai apresentando a sua compreensão do discurso da participante, momento em que surgem questões secundárias (Szymanski et al., 2002). No segundo encontro, a pesquisadora retoma temas que acredita serem importantes para esclarecer dúvidas e falas significativas. Na Entrevista Reflexiva, a pesquisadora não realiza interrupções, e cada participante pode falar o tempo que julgar necessário. Se desejar, pode abordar tópicos que não estejam contemplados nas perguntas norteadoras. Os dois encontros da Entrevista Reflexiva deste estudo aconteceram em sessões individuais, nas dependências da escola, mediados pela pesquisadora principal deste estudo. O local utilizado para as entrevistas foi uma sala disponibilizada pela escola, em que não houvesse interrupção ou que outras pessoas pudessem ter acesso aos encontros. Três meninas optaram por participar dos dois encontros e uma menina, apenas do primeiro.

\section{Análise dos dados}

Para a pré-análise e análise dos dados da Entrevista Reflexiva, foi utilizada a grounded-theory, ou teoria fundamentada nos dados, que permite a produção de uma teoria a partir da experiência estudada (Strauss \& Corbin, 2008).

Nessa forma de análise, é necessária uma interação profunda entre o pesquisador e os dados coletados para, então, serem realizados estes procedimentos: a) codificação aberta, que é o exame linha por linha das transcrições, com vistas a extrair as propriedades e dimensões da experiência em análise; b) codificação axial, por meio da qual se relacionam as categorias às subcategorias, especificam-se as propriedades e dimensões e reagrupam-se dados fragmentados durante a codificação inicial; c) codificação teórica, que se trata do agrupamento final das categorias e subcategorias que se referem ao mesmo 
fenômeno (Strauss \& Corbin, 2008; Charmaz, 2009), normalmente apresentadas por meio de figuras, que apontam claramente as categorias e subcategorias emergidas dos dados.

\section{Considerações éticas}

A pesquisa foi aprovada pelo Comitê de Ética seguindo todas as normas sugeridas, sob Processo n. 43694215.2.0000.5307. Após a aprovação pelo comitê de ética e concordância da escola, todos os adolescentes entre 12 e 17 da escola do turno diurno foram convidados a participar do estudo. Os pais/responsáveis dos alunos interessados assinaram o Termo de Consentimento Livre e Esclarecido (TCLE), e os adolescentes assinaram o Termo de Assentimento (TALE), garantindo-se todos os aspectos éticos, conforme Resolução n. 466, de 12 de dezembro de 2012, do Conselho Nacional de Saúde (Ministério da Saúde, 2012).

Antes de iniciar cada etapa do estudo, todos eram informados sobre os objetivos e o sigilo das informações, além da possibilidade de desistir do estudo a qualquer momento, sem qualquer prejuízo. Tendo em vista que a escola não dispõe de psicólogo, caso houvesse necessidade durante o estudo, um órgão público de apoio especializado poderia ser contatado.

Quanto às adolescentes deste estudo, apenas dois casos de VS eram de conhecimento da família. A pesquisadora solicitou autorização para conversar com alguém de confiança delas, a fim de realizar os encaminhamentos pertinentes, como denúncia aos órgãos competentes e auxílio psicológico. A situação deveria ser conduzida com calma e cuidado, pois a literatura aponta que vítimas de VS podem sofrer danos psicológicos graves por atitudes mal encaminhadas pelos adultos (Furniss, 1993).

\section{Resultados}

Conforme dados obtidos por meio do Questionário de dados sociodemográficos, Questionário sobre bullying (Bandeira, 2009), Questionário Juventude Brasileira (Dell'Aglio et al., 2011) e fichas documentais escolares, descreve-se a seguir o perfil das adolescentes do estudo (nomes fictícios):

- Bela: informou ter 15 anos, ser da cor branca, morar com mãe, irmã e tio, em uma casa própria. Dos residentes, três trabalham fora (incluindo-a). É estudante do nono ano do Ensino Fundamental e repetiu um ano escolar. Sofreu VS por parte de um tio. Declarou-se alvo de bullying. Na ficha 
documental escolar, há relatos de choro compulsivo nas aulas, sem referência a qualquer motivação.

- Cíntia: informou ter 16 anos, ser da cor preta, morar com mãe, pai e dois irmãos e três sobrinhos, em casa própria. Dos residentes, três trabalham fora (excluindo-a). É estudante do nono ano escolar e repetiu duas vezes de ano. Sofreu VS por parte do primo e declarou-se alvo de bullying.

- Gisele: informou ter 17 anos, ser da cor branca, morar com mãe, pai e irmão, em uma casa própria. Dos residentes, três trabalham fora (excluindo-a). É estudante do sétimo ano escolar e já repetiu três vezes de ano. Nos estudos anteriores, informou que sofreu VS por parte do tio materno e declarou-se alvo de bullying. Na ficha escolar, consta que, em 2014, sofreu bullying físico e verbal por parte de um menino.

- Karina: informou ter 12 anos, ser da cor branca, morar com mãe e irmã, em uma casa cedida pelo avô. Dos residentes, uma pessoa trabalha fora (excluindo-a). É estudante do sexto ano escolar e repetiu uma vez de ano. Informou que sofreu VS por parte do tio e declarou-se alvo de bullying. No primeiro encontro, quase não conseguiu se expressar. Não participou do segundo encontro. Nos resultados, não constam relatos da adolescente, o que será retomado na discussão.

Após a análise das questões sociodemográficas, são apresentados os relatos das adolescentes, por meio de figuras com categorias e subcategorias organizadas por emergirem dos dados. Na Entrevista Reflexiva (Szymanski et al., 2002; Yunes \& Szymanski, 2005), além de responderem à pergunta norteadora, as participantes sentiramse à vontade para abordar diferentes tópicos, o que gerou um grande volume de dados. Inicialmente, após a transcrição e o exame minucioso dos relatos, foram selecionados trechos específicos, relacionados ao objetivo do estudo. Posteriormente, esses recortes foram organizados conforme a semelhança das informações, gerando as categorias e subcategorias, nomeadas de forma a conceituar o fenômeno investigado.

Assim sendo, os relatos das adolescentes acerca da sua percepção sobre as relações entre suas experiências de violência sexual e bullying proporcionaram a elaboração das relações dos fenômenos "Violência sexual \& bullying" a partir de três eixos de categorias de análise: "Experiências solitárias de violência sexual", "Experiências relacionais de bullying" e "Relações entre a solidão da violência sexual e 
a sociabilidade do bullying". Em cada eixo, constam as categorias e subcategorias, representadas pelos círculos menores, e palavras ou expressões-chave, que são resumos das falas das participantes, localizados nas extremidades das figuras.

$\mathrm{Na}$ Figura 1, apresenta-se a primeira categoria, denominada "Experiências solitárias de violência sexual", composta das subcategorias "Perfil do agressor", "Segredo e silêncio" e "Consequências".

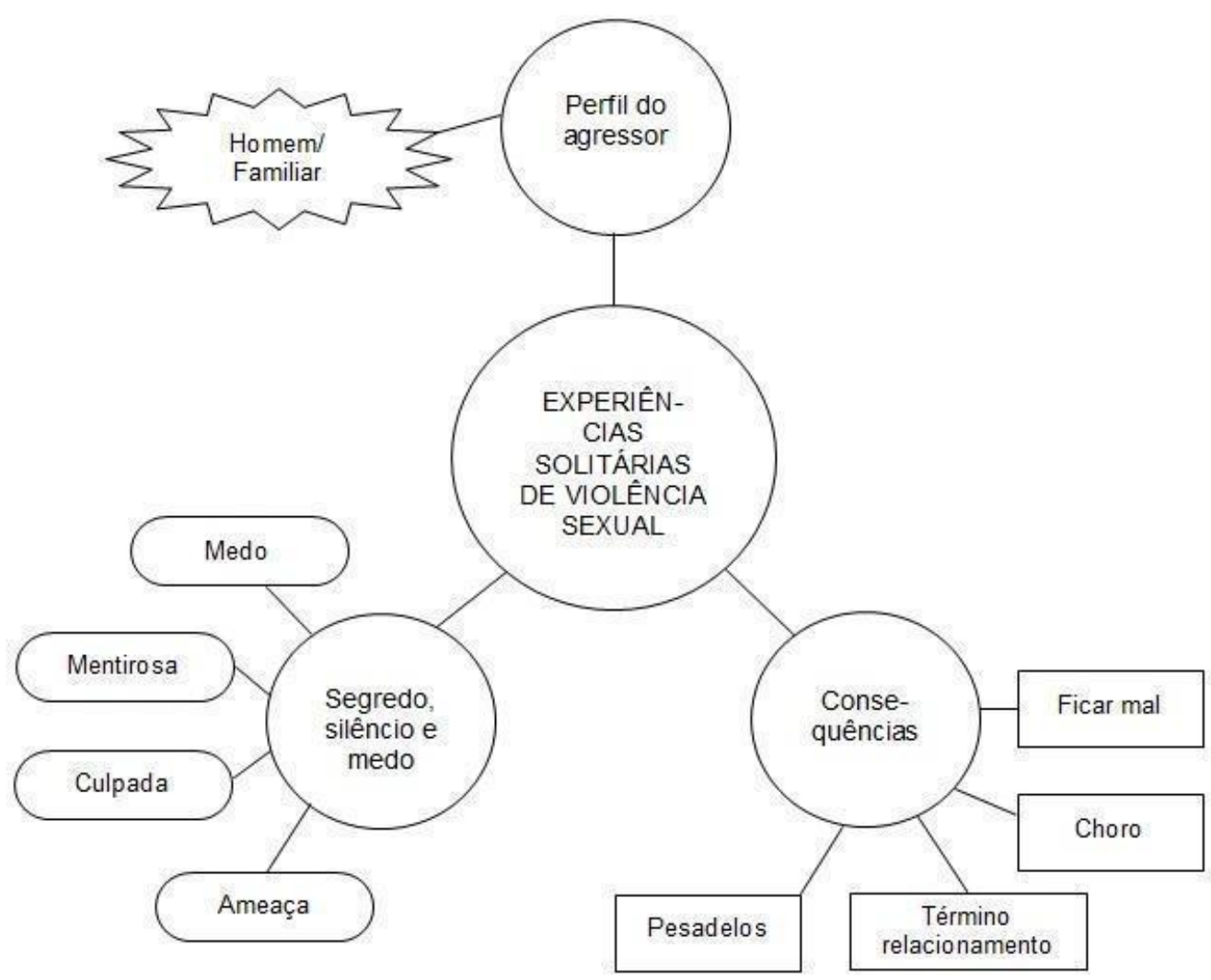
sexual

Figura 1. Eixo e categorias/subcategorias relativa às experiências solitárias de violência

As adolescentes relataram como aconteceram as situações de VS:

"Quando eu era pequena, eu ia na casa da minha vó, minha vó tinha uma lancheria [...]. Só que daí uma vez a minha vó saiu, daí ele [tio materno] pediu pra mim ir no quarto, e daí eu fui, inocente né. [...] E daí ele pegou e trancou a porta e daí a sorte que a minha vó chegou a tempo. [...] É que na verdade não aconteceu só uma vez”. (Bela)

"Quando eu sofri isso, essa violência [por parte do primo], eu tava dentro de casa sozinha [...]. Ele tentou me agarrar à força. Ele saiu, eu não tive reação, eu parei tudo o que eu tava fazendo, fui pro meu quarto... E não saí mais de lá”. (Cíntia) 
As vítimas delinearam o "Perfil do agressor", sendo, em todos os casos, "homem da família" e, na maioria, por serem próximos, estavam numa casa conhecida.

“É filho... é filho de coração [filho da avó que presenciou a VS], é adotivo. É por parte de mãe [Pausa. Chora muito]”. (Bela)

“A mesma história com meu primo, ele fez e ficou seguro porque meu pai acredita nele. É [afirmando que primo é casado]. Tem uma filha. [...] ele fez e ficou seguro porque meu pai acredita nele". (Cíntia)

"Não, é solteiro. Quarenta e sete. Mora com avó. Irmão da mãe. Foi só comigo. Porque eu era da família, acho. Algo assim”. (Gisele)

Karina, que parecia não conseguir expressar-se, apenas confirmou com a cabeça que o agressor sexual era o tio, ou seja, alguém da família, como observado nos estudos anteriores.

As adolescentes também relataram suas tentativas de esconder o fato das outras pessoas da família e de seu mundo social. O relato de uma das participantes mostra que a avó materna da adolescente, mesmo presenciando-a sofrendo a violência, ignorou o fato. O "Segredo, silêncio e medo" compõe o cenário dessas situações, e as adolescentes revelam que mantêm o segredo por medo de serem julgadas "mentirosas", "culpadas" e por sofrerem "ameaças". O silêncio da avófoi interpretado como negligência e descuido.

"Não, ninguém sabe. E a minha mãe... Eu tava com medo de contar pra ela e ela botar a culpa em mim, como sempre. Então eu me fechei, não tive... não tive como contar pra ninguém”. (Bela)

"Meu tio falou se eu contasse pra alguém ele ia fazer mal pra minha irmã, pra minha mãe, pro meu pai, aí eu fiquei com medo de envolver eles”. (Bela)

“A minha vó viu, só que parece que ela não deu importância. [...] Eu não tenho como perdoar ela de todo o meu coração, mas eu respeito ela, só que eu tento, parece, manter distância. E a nossa relação não é boa”. (Bela)

"Com medo, medo até de contar o que acontece, com medo [falando sobre a VS]". (Cíntia)

"Não. Porque ele falava que não era pra contar, ele falava, tu não vai contar pra ninguém, né”. (Gisele)

As falas acima denotam quão difícil e doloroso era para elas silenciarem, sentindose amedrontadas e já enfrentando o sofrimento da crueldade da violência sofrida. Esses formam uma nova categoria que se discutem: as inevitáveis consequências da violência sexual na vida delas. Segundo as adolescentes, lhes é perceptível que a violência sofrida 
gera "Consequências", como "dor", "choro", "pesadelos", tentativas de "término de relacionamento", "ficar mal", ou seja, um desencadear de emoções negativas incontroláveis conforme descrevem as falas a seguir.

“É que eu chorava demais [...]. Dói de lembrar, é muito horrível [muito choro]. Eu fiquei até os 13 anos de idade com medo de noite de acontecer isso, eu tinha pesadelo toda a noite [muito choro]”. (Bela)

"Já tentei terminar com o Mauro (nome fictício), agora mesmo eu tava tentando fazer isso e ele não quer terminar. Eu não tenho mais vontade de namorar, eu sinto, eu não tenho vontade nem de falar com ele mais. É como se o que meu primo fez tá atingindo ele entendeu?". (Cíntia)

"Mal [dizendo como se sente com a VS]". (Gisele)

A segunda categoria, nomeada "Experiências relacionais de bullying", é composta das subcategorias "Formas", "Imagem do autor" e "Consequências", conforme Figura 2 a seguir.

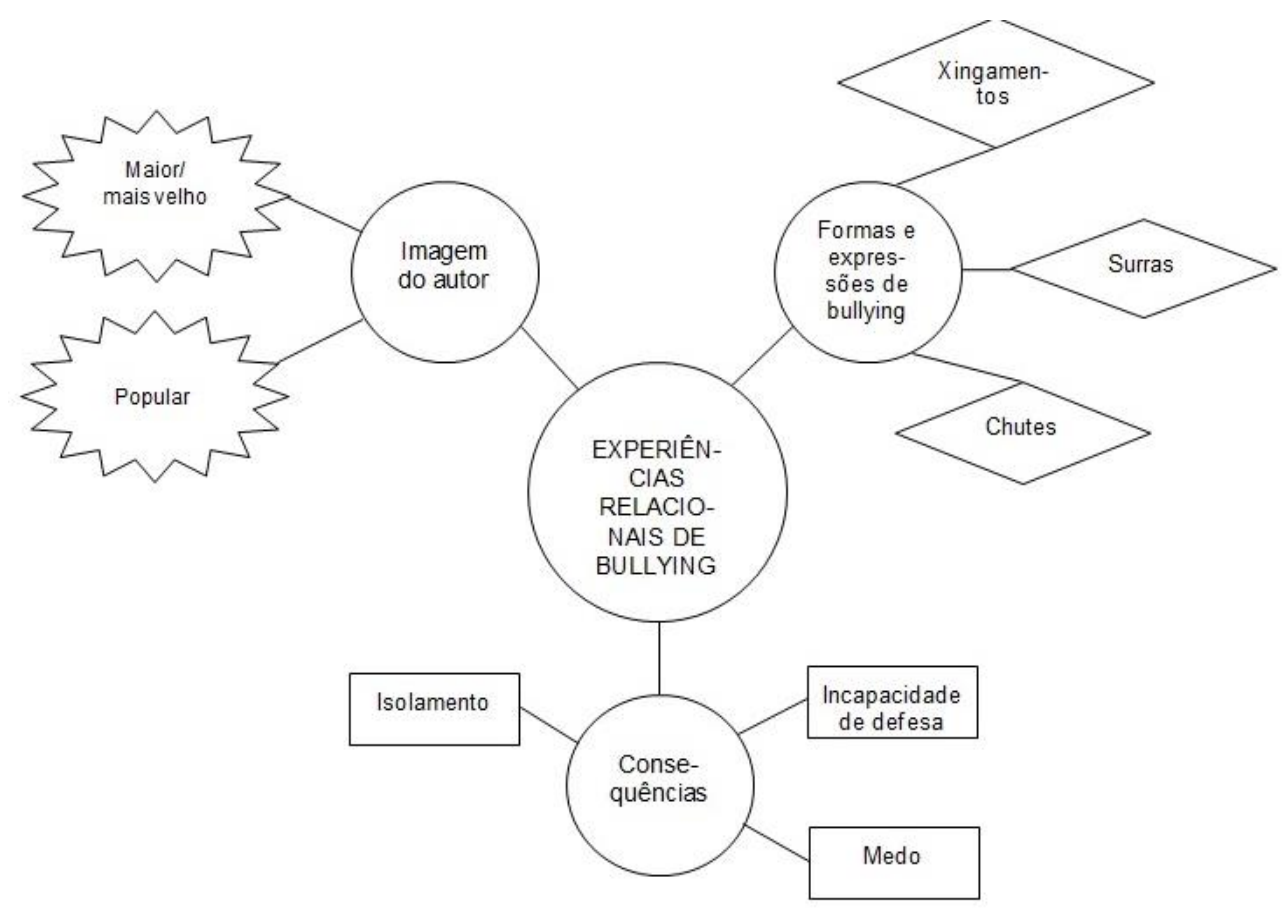
bullying

Figura 2. Eixo e Categorias/subcategorias relativas às experiências relacionais de

Além de abordarem a VS, as meninas relataram as situações relacionais de bullying por elas experienciadas. A partir de então, surgiu a subcategoria "Formas e expressões de bullying", por meio da qual se pode constatar que sofrem com "surras", 
"chutes" e "xingamentos" (e assim como nas experiências de VS, são ignoradas, têm medo e silenciam).

“Teve uma vez que eu saí da escola e elas chegaram a me bater ali perto, então, tipo, ninguém deu bola, entendeu? Todo mundo passava na rua e... uma criança pequena e, tipo, apanhar de uma adolescente, de três ainda, e ninguém fazia nada”. (Bela)

"Mais de uma vez. Ah, um monte de coisa, sora. Me chutava, me xingava". (Gisele)

"Eles debocham de mim, me dão apelido, essas coisas". (Cíntia)

As participantes também definiram a "Imagem do autor", especialmente como alguém "maior e mais velho" e "popular" (isso também coincide nas experiências de VS = mais velho, maior e que as constrange)

"Hoje as gurias, elas eram maiores, então elas se formaram aqui na escola e saíram". (Bela); "Eles são meninos, mas é mais por um que é mais conhecido pela escola". (Cíntia)

O bullying é uma forma de violência que gera "Consequências", como "tristeza" "raiva", "medo" e "incapacidade de defesa", ou seja, sentimentos que deixam marcas negativas conforme as participantes a seguir exemplificam.

"De eu chegar em casa e tá toda marcada e a minha mãe pensou que tivesse acontecido alguma coisa comigo, e eu falar pra minha mãe que não houve nada, sabe, e me trancar no quarto e ficar sem comer. Tantas vezes eu já fiz isso já...”. (Bela).

"Eu fico muito mal com tudo, eu me fecho". (Cíntia).

"Eu não conseguia me defender". (Gisele)

Por fim, a última categoria deste estudo, denominada "Relações entre a solidão da violência sexual e a sociabilidade do bullying", é composta das subcategorias "Escondendo as vivências das violências" e "Integrando as vivências das violências", de acordo com a Figura 3. 


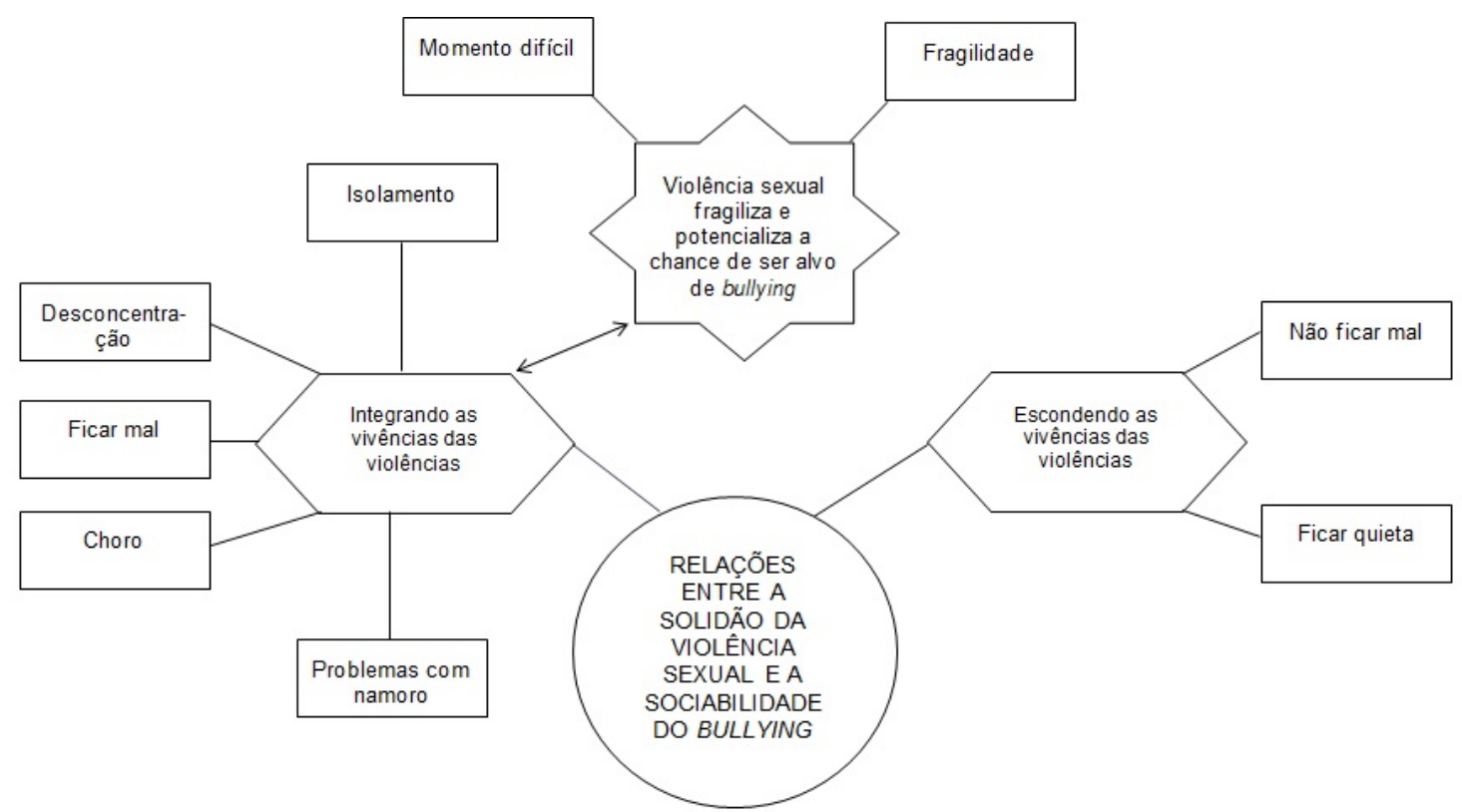

Figura 3. Eixo e categorias/subcategorias relativa às relações entre a solidão da violência sexual e a sociabilidade do bullying.

Quando convidadas a pensar nas relações entre essas duas formas de violência, duas adolescentes declararam que escondem as vivências de violências, adotando atitudes, como "ficar quieta" e "não ficar mal".

"Se todos os problemas, se eu ficar mal por todos os problemas que acontecem em casa [...] eu não conseguiria nem vim mais pra escola porque eu não teria mais força. Então, eu tento separar a escola de casa né. [...] parece que não tem ninguém, sabe, mas ter vergonha de alguma pessoa saber o que eu sofro em casa e rir de mim por causa disso". (Bela)

“Tentei não mostrar pra ninguém o que eu tava sofrendo dentro de casa, tentei ficar, eu fico quieta, não mostro. Eu não sou aquela pessoa de tá falando do que tá acontecendo dentro de casa. Ai, eu tento diferenciar um do outro [...]”. (Cíntia)

Entretanto, as participantes mencionam que acabam por integrar essas vivências de violência nos ambientes escola e família. As adolescentes relatam situações de "isolamento", "desconcentração", "choro", "problemas com namoro" e "ficar mal".

“Tem vezes que, de tanto a gente guardar uma coisa pra nós, por dentro, assim, de agressão, e coisas que mexe com o sentimento, sabe, eu não consigo separar às vezes. Eu fico muito mal, de não conseguir me concentrar nas coisas, de... [...] É difícil tu separar uma coisa da outra, [...] pedofilia ou bullying, não tem como... Tudo, uma coisa liga a outra”. (Bela) 
"Acho que é por causa disso [da VS sofrida], porque não tinha como contar pra ninguém, e minha vó parece que fechou os olhos pra aquilo". (Bela)

"Sim, eu sofro dentro de casa, se eu sofri esse ato dentro de casa, eu trago pro colégio, eu acabo cortando quem quer me ajudar. Eu não tô consigo separar o meu namoro do que acontece na sala de aula e o que acontece dentro de casa". (Cíntia)

"Mal [na escola em relação à violência]. Às vezes eu volto a pensar [na escola]". (Gisele)

Essa dificuldade em dissociar as vivências de violência nos dois microssistemas (escola e família) pode facilitar para que sejam vítimas de bullying. Assim sendo, elaborou-se a ideia de que a "Violência sexual fragiliza e potencializa a chance de ser alvo de bullying". Para as adolescentes, os autores de bullying aproveitaram-se de seu "momento difícil" e de sua "fragilidade" e denotam ter ciência dessa relação.

"Muitas vezes as pessoas aproveitam do meu momento difícil [fragilidade diante da violência] pra fazer o bullying comigo". (Cíntia)

"E daí... acho que... eu li um livro sobre o bullying, e daí... e os agressores sempre procuram a vítima que tá mais frágil e sem ninguém por perto pra atingir ela”. (Bela)

\section{Discussão}

As participantes relataram suas experiências de VS e bullying com detalhes e foram capazes de perceber que tais vivências lhes causam consequências negativas e são capazes de transpor os limites físicos de cada microssistema onde esta é efetivamente praticada.

As adolescentes vítimas de VS em ambiente familiar demonstraram compreender que sofriam a agressão por dois motivos principais: o fato de o agressor ser alguém de confiança da família e as ameaças sofridas não serem só contra si mas também contra seus familiares. Furniss (1993) utiliza o termo "Síndrome do Silêncio" para nomear o uso desses artifícios por parte do agressor para não ser descoberto. As vítimas sentem-se, muitas vezes, extremamente constrangidas em denunciar o caso, especialmente em se tratando de crianças e adolescentes, o que amplia a dificuldade de investigação (Sena et al., 2018). Esse pacto de silêncio, que se fortalece e se reproduz em função do medo de denunciar, também envolve a população e os profissionais (Paixão \& Neto, 2020). Como consequência, há a subnotificação de casos, o que prejudica a ação de redes de proteção e de atendimento, que contam com diferentes serviços nos âmbitos da saúde, assistência social e justiça, capazes de acolher e oferecer os cuidados necessários às vítimas 
(Hohendorff \& Patias, 2017). Por isso, os profissionais que têm contato com crianças e adolescentes têm papel primordial no processo de identificação e escuta das revelações de VS, não devendo calar-se ou descredibilizar a vítima, mas sim ter uma escuta empática e adotar medidas cabíveis em casos suspeitos (Hohendorff \& Patias, 2017).

Embora nem todas as vítimas de VS fiquem perturbadas psiquiatricamente, muitas ficam confusas pelos efeitos da violência, com problemas que podem se prolongar por muito tempo (Furniss, 1993; Hébert et al., 2016). Durante os encontros com a pesquisadora, as adolescentes manifestaram as mudanças que sofreram em decorrência da VS, citando problemas e transtornos, como choro, pesadelos, tentativa de término de relacionamento ou confusão de sentimentos. Ainda que não exista um conjunto de sintomas ou sinais exclusivos apresentado pelas vítimas de VS (Guerra et al., 2018; Hohendorff \& Patias, 2017), um estudo conduzido por Hohendorff e colaboradores (2014) agrupou as consequências frequentemente relatadas: consequências físicas (lesão corporal, mutilações, fissura e dilaceração anal, doenças sexualmente transmissíveis), consequências emocionais (ansiedade, culpa, medo, raiva), consequências cognitivas (autoimagem pobre/baixa autoestima, confusão quanto à identidade de gênero, dificuldade de aprendizagem, dissociação, paranoia, pensamentos obsessivos, pesadelos) e consequências comportamentais (agressividade, baixo rendimento escolar, comportamento autodestrutivo, comportamento externalizante, comportamento regressivo, fugas de casa, ideação e conduta suicida, problemas interpessoais, problemas legais, comportamento hiperssexualizado, sintomas obsessivo-compulsivos), além de psicopatologias. Algumas dessas consequências, como problemas em relacionamentos e sintomas internalizantes, são relatadas pelas adolescentes, que também podem ser potencializados devido ao bullying.

As adolescentes também relataram suas experiências com outra forma de violência, o bullying escolar. Afirmaram que, na escola, sofreram principalmente bullying verbal e físico. Ainda, elaboraram um perfil dos seus agressores como colegas mais velhos e populares, dos quais não conseguiam se defender. A literatura aponta que o autor de bullying escolhe sua vítima: ela precisa estar em uma posição de inferioridade (física ou psicológica) e não ter condições de se defender (Olweus, 1993). O perfil desses autores contribui para essas agressões, pois são alunos com elevada autoestima, pouca empatia, uma visão positiva sobre si próprio e com sentimento de superioridade. Esse poder é um dos fatores que impede as vítimas de se defenderem ou de lidarem com o problema (Berger, 2007; Olweus, 1993, 2019). Portanto, as adolescentes deste estudo são vistas por 
esses agressores como vítimas potenciais, por estarem mais fragilizadas emocionalmente e sem condições de se defender (Olweus, 1993).

Assim como a VS, o bullying gera consequências negativas na vida de quem o sofre (Barzilay et al., 2017; Mello et al., 2017). De forma geral, as participantes afirmaram que se isolaram mais, tiveram dificuldades para se alimentar e "fecharam-se" em si. De fato, as agressões, quando repetidas e acumuladas, podem causar danos de diferentes intensidades nas vítimas, como ansiedade, isolamento, depressão, distúrbios alimentares (Arseneault, 2017; Mello et al., 2017; Stanley et al., 2016), sinalizados neste estudo pelas adolescentes. Por muito tempo, havia por parte da sociedade um certo ceticismo e desconhecimento sobre as consequências do bullying (Arseneault, 2018), com a crença de que era um processo natural de crescimento, algo que crianças e adolescentes deveriam aprender a lidar para tornarem-se mais fortes (Smith, 2018). Atualmente, devido ao vasto campo de estudos teóricos e empíricos sobre o tema, reconhece-se que há efeitos prejudiciais que podem perdurar por longos períodos de tempo (Arseneault, 2018; Barzilay et al., 2017; Mello et al., 2017).

Ao relatarem suas experiências de VS e bullying, as adolescentes perceberam que suas vivências de violência transpassaram os limites do microssistema em que era praticada, ou seja, se sofriam VS no ambiente familiar, a tendência era exteriorizarem sentimentos na escola, junto ao grupo de pares. Com vistas a evitar esse processo, passaram a adotar atitudes de invisibilidade para tentar não demonstrar seus sentimentos, como ficar mais em silêncio na escola, inclusive por medo de algum colega desconfiar do que estavam sofrendo no ambiente familiar. A partir disso, conclui-se que o principal receio era colocar em evidência a violência sofrida na família.

Ainda que tentassem adotar estratégias para evitar que outras pessoas soubessem de suas vivências de violência, os sinais de suas fragilidades transbordavam. Tais comportamentos das adolescentes podem ser considerados estratégias de coping, utilizadas com o intuito de minimizar situações de estresse (Lazarus \& Folkman, 1984). No entanto, essas estratégias foram quase sempre malsucedidas, pois, por mais que tentassem, na maioria das vezes, as adolescentes não conseguiam distinguir o que viviam em um ambiente quando estavam em interação no/com o outro e, assim, manifestavam suas angústias, decepções e medos. As adolescentes declararam que se sentiam mal na escola, tinham dificuldades de se concentrar nas atividades e de separar as vivências de violência. Nesses casos em que não conseguiam administrar as situações estressoras, 
evidenciam-se os processos de risco, os quais, ao se acumularem, aumentaram as chances de apresentarem problemas emocionais e sociais (Rutter, 1987; Yunes, 2007).

Uma pesquisa realizada no Chile com adolescentes vítimas de VS analisou as relações entre fatores de VS, fatores cognitivos e comportamentais e sintomas. Constatouse que a relação entre autoeficácia e sintomas é mediada por estratégias ativas de coping e que a percepção do apoio familiar está positivamente relacionada à autoeficácia e negativamente aos sintomas (Guerra et al., 2018). Portanto, salienta-se o papel relevante da rede de apoio familiar para que essas vítimas adotem estratégias de coping positivas, capazes de contribuir para superação de suas vivências de violência. Acrescentando-se a isso, a partir dos relatos das adolescentes sobre estratégias adotadas no ambiente escolar, entende-se que a escola também tem a tarefa de derrubar as barreiras impostas pelo medo, vergonha e preconceito que acometem tantas vítimas diariamente (Vieira, 2018), constituindo-se num efetivo espaço de proteção.

Analisando-se de forma contextual, ao compreenderem as dificuldades em dissociar as vivências entre os microssistemas família e escola, as adolescentes refletiram que talvez sofressem bullying devido à violência no ambiente familiar. Perceberam suas mudanças comportamentais negativas na escola ou na família, em virtude da violência sofrida no outro ambiente. Assim, demonstraram compreender como se estabelece a relação entre VS e bullying nos principais microssistemas de influência nas suas vidas família e escola. No nível macrossistêmico (Bronfenbrenner, 2011), VS e bullying são campos complexos. No primeiro caso, como observado neste estudo, o abusador mantinha uma relação de poder com sua vítima, ameaçando-a e sentindo-se seguro para cometer tais atos por ser alguém de confiança. Aliado a isso, ainda se tem a concepção de que as vítimas são "culpadas", o que as impede, muitas vezes, de contarem sobre a VS sofrida (Furniss, 1993). Já o bullying, outro problema social que afeta as relações entre pares, apesar de ser um fenômeno antigo (Smith, 2014), ainda é visto como um processo natural de crescimento (Smith, 2018).

O primeiro passo para transformar essa realidade e prevenir toda a forma de violência é sempre oferecer ambientes seguros com interações positivas e significativas (Bronfenbrenner, 2011), que possibilitem a meninas e meninos vítimas de diferentes formas de violência se desenvolvam positivamente. Assim, as pessoas que participam dos microssistemas família e escola podem se tornar redes de apoio importantes a crianças e adolescentes vítimas de violência. Para isso, devem estar atentas para os indícios de violência, ainda que manifestados sutilmente. Somente com esse esforço coletivo poderão 
contribuir para a diminuição dos índices de violência (Leclerc \& Felson, 2016). Neste momento, retoma-se o caso de uma das participantes (Karina) que quase não conseguiu se expressar, apenas indicando com a cabeça positivamente que tinha sofrido VS por parte do tio. Esse silêncio e a dificuldade de se expressar revelam muito sobre como as violências influenciam negativamente a sua vida. Muitas vítimas podem se sentir da mesma forma, tendo dificuldades de verbalizar todo o sofrimento que sentem. Um olhar atento da família e da escola é fundamental para transformar a realidade desta e de tantas outras meninas e meninos vitimizados.

Um passo importante para a prevenção da VS é a elaboração de protocolos e cartilhas que orientam profissionais da saúde e educação a conduzirem situações de violência, como é o caso do Brasil, por meio do seu Ministério da Saúde (2002), e do México, por meio da Secretaría de Educación Pública (2018). O objetivo é apoiar no processo de diagnóstico, registro e notificação de casos de violência (Ministério da Saúde, 2002), como também oferecer um conjunto de ações que visam a modificar favoravelmente os fenômenos psicológicos, ambientais e sociais das crianças e adolescentes vitimizados (Secretaría de Educación Pública, 2018). Quanto ao bullying, no Brasil, está em vigor a Lei 13.185 (2015), a qual determina que escolas devem criar medidas de prevenção a essa forma de violência. A partir de uma abordagem macro e mesossistêmica, deve-se envolver a escola e as famílias. Mais do que tratar vítimas como "sujeitos" passivos de qualquer ação ou programa, estas têm que ser assumidas como cidadãos ou cidadãs de direito, de participação, de decisão com autonomia e protagonismo empoderado e transformador no enfrentamento da VS (Ribeiro et al., 2019) e do bullying escolar em benefício de seu próprio bem-estar e proteção (Forster et al., 2019).

\section{Considerações Finais}

Esta pesquisa teve por objetivo compreender relações entre os efeitos de duas formas de violência, a VS e o bullying, na vida de adolescentes escolares. A maioria das participantes demonstrou compreensão sistêmica das relações de suas experiências com VS e bullying, o que sugere clareza e tentativas de encontrar saídas para os sofrimentos vividos em diferentes contextos e situações.

Para que as pessoas ao seu redor não percebessem sua condição de vítimas de violência, acabavam adotando, em algum momento de suas vidas, estratégias de coping, as quais, muitas vezes, não produziam o resultado esperado. Por demonstrarem suas 
angústias e fraquezas no ambiente escolar, podiam se tornar alvos fáceis de bullying, tendo em vista que os autores observavam as fragilidades das potenciais vítimas.

Como observou-se neste estudo, as duas formas de violência não podem ser analisadas separadamente, tendo em vista seu aspecto sistêmico, ecológico e integrado. Bronfenbrenner (2011) ressalta a importância de se pesquisar, conjuntamente, pelo menos dois microssistemas, pois, com sua teoria bioecológica, demonstra que as vivências em um ambiente refletem no(s) outro(s), o que se comprova nesta pesquisa.

Este estudo apresenta algumas limitações. Primeiramente, ressalta-se o reduzido número de participantes, sendo apenas meninas. Nesse caso, não se generalizam os resultados obtidos nem os relacionamos, por exemplo, ao sexo masculino. Em se tratando de VS envolvendo meninos, há outros aspectos envolvidos, como a estigmatização, ao se questionar a orientação sexual e a identidade de gênero das vítimas, o que também pode levá-los a não revelar a violência (Hohendorff \& Patias, 2017). Ressaltamos que o presente estudo fez a análise das experiências e percepções das participantes, o que pode sugerir uma segunda limitação na forma de coleta de dados, constituída pelo autorrelato. De fato, pode não haver correspondência exata entre o comportamento real e o que está sendo verbalizado. Assim, para outros estudos, a sugestão é utilizar metodologias combinadas (Kohlsdorf \& Costa Junior, 2009).

Mesmo que o estudo apresente limitações, acredita-se que é um tema relevante e atual, pois ainda há poucas pesquisas que exploram as relações entre ambos os fenômenos - VS e bullying (Hébert et al., 2016; Fernandes et al., 2020). Além disso, ofereceu-se um espaço importante para que as adolescentes relatassem suas vivências de violência com segurança e escuta sensível, sem interrupções, julgamentos e pré-conceitos, falas estas de extrema importância, pois mostram a educadores, profissionais da saúde e gestores de órgãos públicos como se dá essa dinâmica entre VS e bullying.

A violência pode ser evitada na família e na escola se os adultos mantiverem relações proximais positivas, enriquecedoras e saudáveis com as crianças. Usar estratégias que envolvam os alunos com fatores de proteção e estimulem habilidades saudáveis são a forma mais eficaz de ajudá-los a enfrentar os desafios diários e evitar problemas relacionados à violência (Secretaría de Educación Pública, 2018). Para que a sociedade possa atuar no desenvolvimento saudável de crianças e adolescentes escolares, projetos de intervenção positiva e políticas públicas devem ser direcionados de forma associada e interconectada, gerando uma comunicação propositiva e protetora entre escola e família. 


\section{Referências}

Arseneault, L. (2017). The long-term impact of bullying victimization on mental health. World Psychiatry, 16(1), 27-28. http://dx.doi.org/10.1002/wps.20399

Arseneault, L. (2018). Annual Research Review: the persistent and pervasive impact of being bullied in childhood and adolescence: implications for policy and practice. Journal of Child Psychology and Psychiatry, 59(4), 405-421. http://dx.doi.org/10.1111/jcpp.12841

Azevedo, M. B., Alves, M. S.; \& Tavares, J. R. F. (2018). Abuso sexual intrafamiliar em adolescentes e suas reflexões. Psicología para América Latina, 30, 7-25. http://pepsic.bvsalud.org/pdf/psilat/n30/a02n30.pdf

Bandeira, C. M. (2009). Bullying: auto-estima e diferenças de gênero. Dissertação de Mestrado, Universidade Federal do Rio Grande do Sul, Porto Alegre. http://www.lume.ufrgs.br/bitstream/handle/10183/23014/000741093.pdf?seq $\underline{\text { uence }=1}$

Bandeira, C. M., \& Hutz, C. S. (2010). As implicações do bullying na auto-estima de adolescentes. Revista Semestral da Associação Brasileira de Psicologia Escolar e Educacional, 14(1), 131-138. https://www.scielo.br/pdf/pee/v14n1/v14n1a14.pdf

Barzilay, S., Brunstein, K. A., Apter, A., Carli, V., Wasserman, C., \& Hadlaczky, G. (2017). Bullying victimization and suicide ideation and behavior among adolescents in Europe: a 10-Country Study. Journal of Adolescent Health, 61, 179-186. https://doi.org/10.1016/j.jadohealth.2017.02.002

Berger, K. S. (2007). Update on bullying at school: science forgotten?. Developmental Review, 27, 90-126. http://dx.doi.org/10.1016/j.dr.2006.08.002

Bronfenbrenner, U. (1996). A ecologia do desenvolvimento humano: experimentos naturais e planejados. Tradução de Maria Adriana Veríssimo Veronese. Porto Alegre, RS: Artes Médicas.

Bronfenbrenner, U. (2011). Bioecologia do desenvolvimento humano: tornando os seres humanos mais humanos. Tradução de André de Carvalho Barreto. Porto Alegre, RS: Artmed.

República Federativa do Brasil (1998). Constituição da República Federativa do Brasil de 1988. http://www.planalto.gov.br/ccivil_03/constituicao/constituicao.htm

Cowie, H. (2014). Understanding the role of bystanders and peer support in school bullying. The International Journal of Emotional Education, 6(1), 26-32. https://files.eric.ed.gov/fulltext/EJ1085728.pdf

Dell'Aglio, D. D., Koller, S. H., Cerqueira-Santos, E., \& Colaço, V. F. R. (2011). Revisando o Questionário da Juventude Brasileira: uma nova proposta. In D. D. Dell'Aglio \& S. H. Koller (Orgs.). Adolescência e Juventude: vulnerabilidade e contextos de proteção (pp. 259-270). São Paulo, SP: Casa do Psicólogo.

Deslandes, S. F., Vieira, L. J. E. S., Cavalcanti, L. F., \& Silva, R. M. (2016). Health care of children and adolescents in situation of sexual violence, in four Brazilian capitals. Interface, 20(59), 865-77. http://dx.doi.org/10.1590/1807$\underline{57622015.0405}$

Fernandes, G., Yunes, M. A. M., \& Finkler, L. (2016). Percepções de adolescentes escolares sobre as relações entre violência doméstica e bullying. Revista Psicologia Política, 16(36), 153-168. 
http://pepsic.bvsalud.org/scielo.php?script=sci_arttext\&pid=S1519549X2016000200003

Fernandes, G., Yunes, M. A. M., \& Finkler, L. (2020). The support networks of adolescent victims of domestic violence and bullying. Paidéia, 30, e3007. http://dx.doi.org/10.1590/1982-4327e3007

Forster, M., Gower, A. L., Gloppen, K., Sieving, R., Oliphant, J., Plowman, S., Gadea, A., \& MacMorris, B. (2019). Associations between dimensions of school engagement and bullying victimization and perpetration among middle school students. School Mental Health. Advance online publication. https://doi.org/10.1007/s12310-019-09350-0

Furniss, T. (1993). Abuso sexual da criança: uma abordagem multidisciplinar. Tradução de Maria Adriana Veríssimo Veronese. Porto Alegre, RS: Artes Médicas.

Guerra, C., Farkas, C., \& Moncada, L. (2018). Depression, anxiety and PTSD in sexually abused adolescents: Association with self-efficacy, coping and family support. Child Abuse \& Neglect, 76, 310-320. http://dx.doi.org/10.1016/j.chiabu.2017.11.013

Hébert, M., Cénat, J. M., Blais, M., Lavoie, F., \& Guerrier, M. (2016). Child sexual abuse, bullying, cyberbullying, and mental health problems among high schools students: a moderated mediated model. Depression and Anxiety, 33(7), 623-629. http://dx.doi.org/10.1002/da.22504

Hohendorff, J. V., Habigzang, L. F., \& Koller, S. H. (2014). Violência sexual contra meninos: teoria e intervenção. Curitiba, PR: Juruá.

Hohendorff, J. V; \& Patias N. D. (2017). Violência sexual contra crianças e adolescentes: identificação, consequências e indicações de manejo. Barbarói, 49, 239-257. http://dx.doi.org/10.17058/barbaroi.v0i49.9474

Hoppe, M. M. W. (1998). Redes de apoio social e afetivo de crianças em situação de pobreza. Dissertação de Mestrado, Programa de Pós-Graduação em Psicologia do Desenvolvimento, Universidade Federal do Rio Grande do Sul, 1998.

Hoppe, M., \& Ramos, K. (2012). Redes de apoio social e intersetorialidade entre educação e saúde nos anos iniciais do ensino fundamental. Revista Educação, Cultura e Sociedade, 2(2), 47-62.

http://sinop.unemat.br/projetos/revista/index.php/educacao/article/view/1000/ $\underline{703}$

Kohlsdorf, M., \& Costa Junior, A. L. (2009). O autorrelato na pesquisa em psicologia da saúde: desafios metodológicos. Psicologia Argumento, 27 (57), 131-139. http://www2.pucpr.br/reol/pb/index.php/pa?dd99=issue\&dd0=169

Lazarus, R. S., \& Folkman, S. (1984). Stress, Appraisal, and Coping. New York, NY: Springer.

Leclerc, B., \& Felson, M. (2016). Routine Activities Preceding Adolescent Sexual Abuse of Younger Children. Sexual Abuse: A Journal of Research and Treatment, 28(2), 116-131. http://dx.doi.org/10.1177/1079063214544331

Lei n. 8.069, de 13 de julho de 1990. Dispõe sobre o Estatuto da Criança e do Adolescente e dá outras providências. Diário Oficial da União, Brasília, DF. http://www.planalto.gov.br/ccivil_03/leis/18069.htm

Lei n. 13.185, de 06 de novembro de 2015. (2015). Institui o Programa de Combate à Intimidação Sistemática (Bullying). Diário Oficial da União, Brasília, DF. http://www.planalto.gov.br/ccivil_03/_ato2015-2018/2015/lei/113185.htm 
Magalhães, J. R. F., Gomes, N. P., Campos, L. M., Camargo, C. L., Estrela, F. M., \& Couto, T. M. (2017). Expressão da violência intrafamiliar: história oral de adolescentes. Texto \& Contexto Enfermagem, 26(4), 1-9. http://dx.doi.org/10.1590/0104-07072017001730016

Marzol, R. M.; Bonafé, L., \& Yunes, M. A. M. (2012). As perspectivas de crianças e adolescentes em situação de acolhimento sobre cuidadores protetores. Psico, 43(3), 317-324. http://revistaseletronicas.pucrs.br/ojs/index.php/revistapsico/article/view/798 $\underline{8 / 8232}$

Mello, F. C. M., Silva, J. L., Oliveira, W. A., Prado, R. R., Malta, D. C., \& Silva, M. A. I. (2017). A prática de bullying entre escolares brasileiros e fatores associados, Pesquisa Nacional de Saúde do Escolar 2015. Ciência \& Saúde Coletiva, 22(9), 2939-2948. http://dx.doi.org/10.1590/1413$\underline{81232017229.12762017}$

Ministério da Saúde. Conselho Nacional de Saúde. (2012). Resolução N. 466, de 12 de dezembro de 2012. http://bvsms.saude.gov.br/bvs/saudelegis/cns/2013/res0466_12_12_2012.htm 1

Ministério da Saúde. Secretaria de Assistência à Saúde. (2002). Notificação de maustratos contra crianças e adolescentes pelos profissionais de saúde: Um passo a mais na cidadania em saúde. Brasília: Secretaria de Assistência à Saúde. http://bvsms.saude.gov.br/bvs/publicacoes/notificacao_maustratos_criancas_a dolescentes.pdf

Olweus, D. (1993). Bullying at school. Oxford, USA: Blackwell Publishing.

Olweus, D. (2019). The Olweus Bullying Prevention Program (OBPP): new evaluation and current status. In P. K. Smith (Ed.), Making an impact on school bullying: interventions and recommendations (pp 23-44). Abingdon, Oxon; New York, NY: Routledge.

Paixão, E. S., \& Neto, J. C. S. (2020). O abuso sexual de crianças e adolescentes: considerações sobre o fenômeno. Territorium, 27(I), 97-111. https://doi.org/10.14195/1647-7723_27-1_8

Reisen, A., Viana, M. C., \& Santos-Neto, E. T. (2019). Bullying among adolescents: are the victims also perpetrators?. Brazilian Journal of Psychiatry, 41(6), 518-529. http://dx.doi.org/10.1590/1516-4446-2018-0246

Ribeiro, J. H. S., Coimbra, S. M. G., \& Leme, V. B. R. (2018). Violência sexual contra crianças e adolescentes: resiliência e protagonismo na Amazônia. Revista de Psicología, 2, 215-226. http://dehesa.unex.es/handle/10662/10608

Rutter, M. (1987). Psychosocial resilience and protective mechanisms. American Journal of Orthopsychiatry, 57(3), 316-331.

Salmivalli, C. (2010). Bullying and the peer group: a review. Aggression and Violent Behaviour, 15(2), 112-120. http://dx.doi.org/10.1016/j.avb.2009.08.007

Santos, M. J., Mascarenhas, M. D. M., Malta, D. C., Lima, C. M., \& Silva, M. M. A. (2019). Prevalência de violência sexual e fatores associados entre estudantes do ensino fundamental - Brasil, 2015. Ciência \& Saúde Coletiva, 24(2), 535544. http://dx.doi.org/10.1590/1413-81232018242.13112017

Secretaría de Educación Pública. (2018). Protocolos de prevención, detección y actuación en casos de abuso sexual infantil, acoso escolar y maltrato, en escuelas de Educación Básica. Estado de Sonora. México: Gobierno de México/SEP/Programa Nacional de Convivencia Escolar. 
https://4.files.edl.io/3ff2/10/09/18/134326-3da56135-8a6d-4aa3-a103$188 \mathrm{~d} 0 \mathrm{~cd} 3 \mathrm{c} 6 \mathrm{c} 4 . \mathrm{pdf}$

Sena, C. A., Silva, M. A., \& Neto, G. H. F. (2018). Incidência de violência sexual em crianças e adolescentes em Recife/Pernambuco no biênio 2012-2013. Ciência \& Saúde Coletiva, 23(5), 1591-1599. http://dx.doi.org/10.1590/1413$\underline{81232018235.18662016}$

Siqueira, A. C., Betts, M. K., \& Dell'Aglio, D. D. (2006). A Rede de apoio social e afetivo de adolescentes institucionalizados no sul do Brasil. Revista Interamericana de Psicología, 40(2), 149-158. http://www.redalyc.org/articulo.oa?id=28440202

Smith, P. K. (2014). Understanding school bullying: its nature \& prevention strategies. London, UK: Sage.

Smith, P. K. (2018). Commentary: types of bullying, types of intervention: reflections on Arseneault. Journal of Child Psychology and Psychiatry, 59(4), 422-423. http://dx.doi.org/10.1111/jcpp.12897

Souza, E. R., \& Minayo, M. C. S. (Orgs.) (2005). Impacto da violência na saúde dos brasileiros. Brasília, DF: Ministério da Saúde. http://bvsms.saude.gov.br/bvs/publicacoes/impacto_violencia.pdf

Stanley, I. H., Horowitz, L. M., Bridge, J. A., Wharff, E. A., Pao, M., \& Teach, S. J. (2016). Bullying and Suicide Risk among Pediatric Emergency Department Patients. Pediatric Emergency Care, 32(6), 347-351. http://dx.doi.org/10.1097/PEC.0000000000000537

Strauss, A., \& Corbin, J. (2008). Pesquisa qualitativa: técnicas e procedimentos para o desenvolvimento da teoria fundamentada ( 2 a ed.). Porto Alegre, RS: Artmed.

Szymanski, H. (2004). Práticas educativas familiares: a família como foco de atenção psicoeducacional. Estudos de Psicologia, 21(2), 5-16. http://www.scielo.br/pdf/estpsi/v21n2/a01v21n2.pdf

Szymanski, H., Almeida, L. R., \& Prandini, R. C. A. R. (2002). A Entrevista na Pesquisa em Educação: a prática reflexiva. Brasília, DF: Plano.

Vaughn, M. G., Fu, Q., Bender, K., DeLisi, M., Beaver, K. M., \& Perron, B. E. (2010). Psychiatric correlates of bullying in the United States: findings from a national sample. Psychiatric Quarterly, 81, 183-195. http://dx.doi.org/10.1007/s11126-010-9128-0

Vieira, M. S. (2018). Violência sexual contra meninas: do silêncio ao enfrentamento. Revista Libertas, 18(2), 101-116. https://periodicos.ufjf.br/index.php/libertas/article/view/18596/9722

Volk, A. A., Dane, A. V., \& Marini, Z. A. (2014). What is bullying? A theoretical redefinition. Developmental Review, 34, 327-343. http://dx.doi.org/10.1016/j.dr.2014.09.001

Yunes, M. A. M. (2007). The ideological trap of the advocacy's discourse on resilience in poor families. E-Journal of Applied Psychology, 3, 26-33. http://dx.doi.org/10.7790/EJAP.V3I1.77

Yunes, M. A. M. \& Szymanski, H. (2005). Entrevista Reflexiva \& GroundedTheory: estratégias metodológicas para compreensão da resiliência em famílias. Revista Interamericana de Psicologia, 39(3), 431-38. https://www.redalyc.org/pdf/284/28439313.pdf

World Health Organization (WHO). (2006). Preventing child maltreatment: A guide to taking action and generating evidence. Geneva, Switzerland: 
WHO/ISPCAN.

http://apps.who.int/iris/bitstream/10665/43499/1/9241594365_eng.pdf2016

Zappe, J. G., \& Dell'Aglio, D. D. (2016). Risco e proteção no desenvolvimento de adolescentes que vivem em diferentes contextos: família e institucionalização. Revista Colombiana de Psicologia, 25(2), 289-305.

http://dx.doi.org/10.15446/rcp.v25n2.51256

Received: 2017-10-10

Accepted: 2021-04-29 